\title{
BONE ATROPHY: A CLINICAL STUDY OF THE CHANGES IN BONE WHICH RESULT FROM NONUSE*
}

\author{
NATHANIEL ALLISON, M.D., AND BARNEY BROOKS, M.D. \\ ST. LOUIS
}

I. Introduction :

(1) Summary of previous experimental study;

(2) Object of present study.

II. Material studied:

(1) Adults ;

(2) Children.

III. Relation between changes in bone as a result of lack of use and the cause of the nonuse.

IV. Character of changes in adults.

V. Character of changes during period of growth.

VI. Effect of nonuse on growth of bone.

VII. Effect of nonuse on regeneration of bone.

VIII. Recovery from bone atrophy.

IX. Summary.

\section{INTRODUCTION}

In a previous experimental study of the atrophic changes in bone which follow nonuse of an extremity, it was found that these changes were the same following nerve paralysis, joint injury and mechanic fixation of the extremity. The degree of atrophy of the bone was directly proportional to the degree of nonuse, regardless of the experimental method used to produce nonuse. Mechanical fixation produced as rapidly developing and as marked bone atrophy as nonuse due to section of nerves or injury to joints.

In this experimental study it was found that nonuse of an extremity of an adult resulted in the bones of this extremity becoming lighter, more fragile and more permeable to the roentgen ray. The length of the bones in adults was unchanged. The diameter of the shaft of the bone was slightly diminished. The diameter of the medullary canal was markedly increased. The cortex of the shaft was thus diminished in thickness. The trabeculae of the spongy bone became thinner, and in part disappeared. In prolonged nonuse, the cortical bone of the shaft became porous. If the period of nonuse of an extremity was concurrent with the period of growth of the individual, the processes of atrophy and growth operated together, and the bones of the nonused

\footnotetext{
* From the Department of Surgery, Washington University School of Medicine.
} 
extremity showed not only the same initial changes as were found in the bones of the adults, but also changes which were the result of an inhibition of growth. The bones were relatively shortened; the diameter of the shafts was diminished; the diameter of the medullary canals was relatively increased, and the shape of the bones was altered. The power of regeneration, the chemical composition and the physical characteristics of bone as a tissue were not changed by nonuse.

In this experimental study, the conclusion was therefore reached that the process of bone atrophy was not a change in the characteristics of bone as a substance but that the process of bone atrophy is a change in the amount of bone present. The process of bone atrophy affects the size, shape, thickness, length, weight and texture of the whole bone; but the chemical composition, the physical characteristics and the regeneration of bone are not changed. Bone atrophy is a quantitative rather than a qualitative change.

The object of this study was to observe the changes in bone which rest1t from lack of use of extremities in various clinical conditions, and to compare these observations with those made on experimental animals.

\section{THE MATERIAL STUDIED}

The material which was studied consisted of the following groups of cases: (1) poliomyelitis; (2) spastic paralysis; (3) peripheral nerve injuries; (4) Friedreich's ataxia; (5) pseudomuscular atrophy; (6) syringomyelia; (7) chronic infectious arthritis; (8) tuberculosis of bone; (9) acute pyogenic osteomyelitis; (10) ischemic contracture; (11) fracture; (12) congenital deformities, and (13) astasia abasia.

In those groups in which a large number of persons were available, cases were selected so as to include various ages and periods of existence of the disabling disease. In all cases, the age, the duration of the disability and the extent of the disability were obtained. When the lack of use was unilateral, the bones of both the used and nonused extremities were studied. The bones were studied by means of roentgen-ray examination. In some instances the bones were available for gross and microscopic study. The bones were studied as to length, thickness, diameter of the medullary canal, thickness of the cortex of the shaft and the number and thickness of the trabeculae of the cancellous bone. In children the epiphyseal cartilages were compared as to regularity and thickness. It was, of course, fully realized that measurements of bones from roentgenograms is at best not accurate; but great care was taken to have the bones as nearly as possible in the same position, and at the same distance from the tube and plate. Thus the measurements were accurate for comparison.

Changes in Bone Resulting from Nonuse in Adults.-The following examples illustrate the changes in bone in adults which result from lack of use: 
CASE 1.-P'ripheral nere injury. A colored man, aged 26, two years previously had caught his left arm in a belt on a revolving wheel, following which there was complete motor and sensory paralysis of the entire left forearm and a motor paralysis of the left arm. There was no bone injury. Sixteen months previously the brachial plexus had been sutured. Since operation there had heen only a slight recovery from the motor paralysis of the arm, and no recovery of motion in the forearm. Sensation was completely recovered slowly in the entire extremity. Examination revealed marked muscle atrophy of the entire extremity with no contractures.

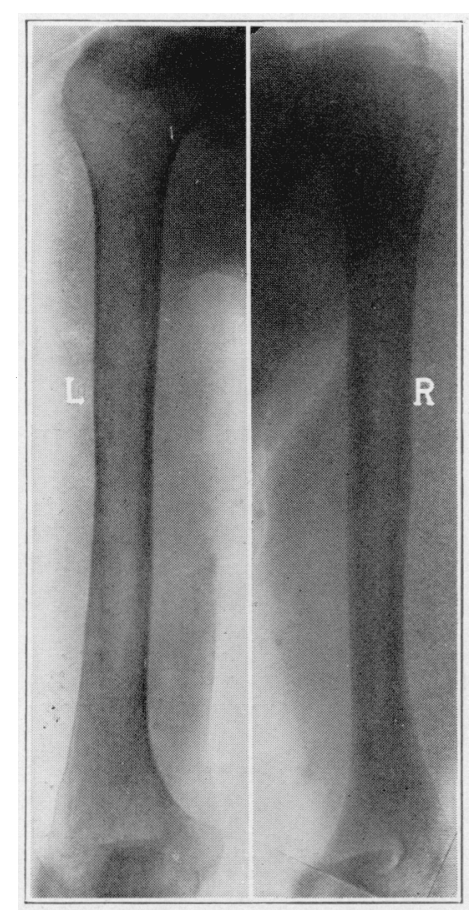

Fig. 1.-Roentgenogram of the right and left humerus in Case 1, a man, aged 26, with a brachial plexus injury of two years' duration. The marked diminution in thickness of the cortex of the shaft and of the left humerus, and the decreased density of the cancellous bone may be noted. The diameter of the medullary canal is markedly increased and the entire thickness of the shaft is slightly decreased. Compare the illustrations with the measurements recorded in the description of Case 1.

Roentgenograms of both humeri were studied. The right humerus appeared normal. The left humerus showed marked thinning of the cancellous bone of its extremities. There was a marked increase in the diameter of the medullary canal with a corresponding thinning of the cortical bone of the shaft. On close inspection linear striae of decreased density were noted in the cortical bone of the shaft (Fig. 1). 
CASE 2.-Spastic paralysis. A man, aged 60, had an apoplectic stroke, thirteen months previously, which resulted in a complete right hemiplegia. Three months after onset, he was able to walk. There had been a gradual improvement in both the arm and leg. He was able to walk with only a slight limp at the time of examination. The right hand, however, had not recovered to the point of usefulness. There was a moderate flexion contracture of the hand and wrist. There was no demonstrable muscle atrophy. The circumferences of the forearms and calves were equal on the two sides. There was voluntary power in all muscles of the right arm and forearm.

Two years previously the patient had fractured the left radius near the wrist joint. From this injury there was a prompt and complete recovery.

Roentgenograms of both forearms and hands were studied. There was a very striking difference in the roentgenograms of the two hands. All of the bones of the right hand showed marked thinning of the cortex of the shafts due to increased diameters of the medullary cavities. The trabeculae of the cancellous bone were fewer in number and thinner. The shafts of the bones

TABle 1.-Measurements of Bones in Case 1

\begin{tabular}{|c|c|c|}
\hline Length & $\begin{array}{c}\text { Right, } \mathrm{Cm} . \\
32.0\end{array}$ & $\begin{array}{c}\text { Left, Cm. } \\
32.0\end{array}$ \\
\hline 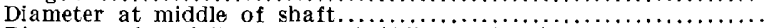 & 2.3 & 2.1 \\
\hline 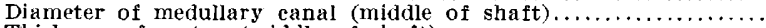 & 1.1 & 1.6 \\
\hline 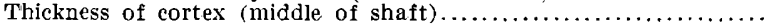 & 0.6 & 0.25 \\
\hline
\end{tabular}

TABLE 2.-Measurements of Bones in Case 3

\begin{tabular}{|c|c|c|c|c|}
\hline & $\begin{array}{c}\text { Right Radius, } \\
\text { Cm. }\end{array}$ & $\begin{array}{c}\text { Left Radius, } \\
\text { Cnl. }\end{array}$ & $\begin{array}{c}\text { Right 'I'ibia, } \\
\text { Cm. }\end{array}$ & $\begin{array}{l}\text { Left Tibia, } \\
\text { Cm. }\end{array}$ \\
\hline Length $\ldots \ldots \ldots \ldots \ldots \ldots \ldots \ldots \ldots \ldots$ & 24.1 & 24.6 & 37.5 & 3 ' .3 \\
\hline Diameter of shaft................ & 1.7 & $1 . \overline{5}$ & 3.1 & 2.6 \\
\hline Diameter of medullary canal............ & 0.7 & 0.6 & & \\
\hline Thickness of cortex................. & $0 . \bar{j}$ & $0.4 \overline{5}$ & & \\
\hline
\end{tabular}

showed evidences of increased porosity as well as decrease in thickness. A difference in the bones of the forearm was distinct but less marked than it was in the bones of the hand. The left radius showed a healed Colles' fracture.

The contracture of the right hand did not permit the taking of roentgenograms from which comparative measurements would have been of any value (Fig. 2).

CASE 3.-Syringomyelia. A white man, aged 38, at the age of 14 years, noticed a weakness in the left arm. At 17 years of age, a weakness of the left leg was noticed. There was a similar weakness in the right arm and right leg at the ages of 29 and 32 . The weakness progressed until eight years previously, when he could get about only with assistance. For the last two years the patient had been able to get only from a bed to a chair. On examination he presented the characteristic picture of advanced syringomyelia, with marked muscle weakness and muscle atrophy of the extremities. There was a complete dissociation of sensation, but no complete muscle paralysis. The skin of both hands and feet showed typical "trophic" ulcers.

Roentgenograms of all the bones of the extremities were studied.

The bones of both arms and legs showed abnormal thinness of the cortex of the shafts and of the cancellous bone of the extremities. The cortical bone of the shafts of all bones was slightly more porous than normally. In gen. 
eral the bone atrophy was not advanced. There was, however, a definite correspondence in the amount of bone atrophy and the extent of loss of function in the extremities. There was no evidence of any influence on the normal growth of the bones in length or shape (Fig. 3).

CASE 4.-Ischemic contracture. A white boy, aged 16 years, one year previously fell and fractured the left radius. Splints were applied and a typical ischemic contracture developed. On examination there was a flexion contracture of the left hand and wrist with marked muscle atrophy and complete

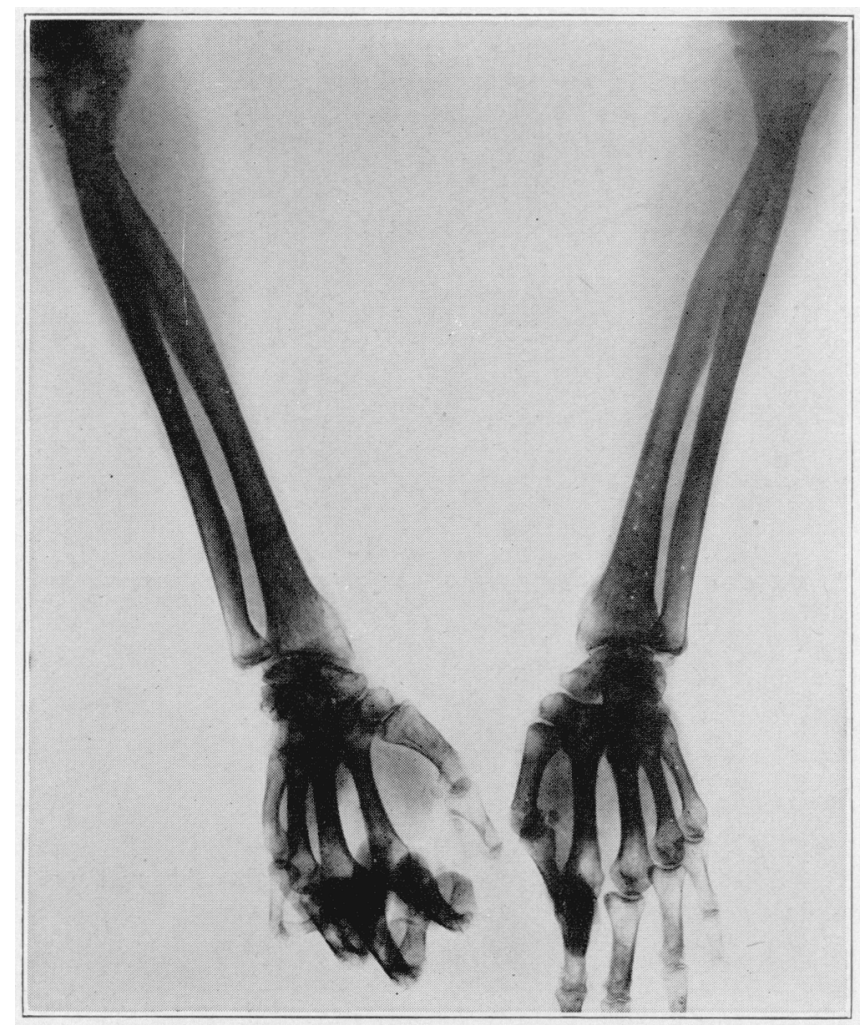

Fig. 2.-Roentgenogram of the bones of the forearms and hands in Case 2, a man, aged 60 , suffering from a right hemiplegia of thirteen months' duration. The atrophic changes in the bones of the right extremity are not so well shown in the reproductions as in the original plates. A marked difference, however, can be seen in the appearance of the right and left first metatarsal bones.

disability. There was very slight motion in the fingers. The contracture was overcome by excision of the carpus. Roentgenograms were made of both forearms and hands after the contracture had been relieved.

The bones of the left hand and forearm showed marked bone changes. There was a healed fracture of the radius in the distal third. The cancellous bone of the distal ends of the radius and ulna was markedly thin. There was 
thinning of the cortex of the shafts of all the bones in the hand and forearm. The diameter of the shafts of all bones was slightly decreased. There was a decrease in length of both bones of the forearm. The epiphyseal lines were completely absent in all bones of the left forearm. The distal epiphyseal line of the right radius was present.

CASE 5.-Infectious arthritis. A white woman, aged 52, six years previously received a crushing injury to her right foot, which was followed by an infection of the tarsal bones. The infection resulted in destruction of the cuneiform bones and parts of the astragalus and os calcis. The infection healed with an extreme valgus deformity of the foot. There was no infection of the tilia or fibula. The patient had not used the right leg since the injury. She got about on the left leg with the assistance of crutches. There was marked muscle atrophy in the right calf. Roentgenograms of both tibias were studied.

There was a very marked difference in the appearance of the two tibias. The left tibia appeared normal. The right tibia showed extreme thinning of

TABle 3.-Measurements of Bones in Case 4

\begin{tabular}{|c|c|c|c|c|}
\hline \multirow{2}{*}{\multicolumn{3}{|c|}{ 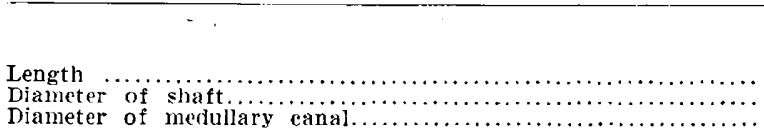 }} & \multirow{2}{*}{$\begin{array}{c}\text { Right Radius, } \\
\text { Cm. } \\
23.4\end{array}$} & \multirow{2}{*}{$\begin{array}{l}\text { Left Radius, } \\
\text { Cm. } \\
22.4\end{array}$} \\
\hline \multicolumn{3}{|c|}{ 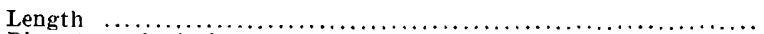 } & & \\
\hline \multicolumn{3}{|c|}{ 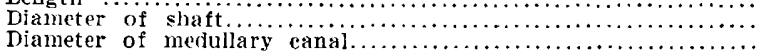 } & 1.3 & 1.1 \\
\hline & & & 0.6 & 0.5 \\
\hline
\end{tabular}

TABle 4.-Measurements of Bones in Case 5

\begin{tabular}{|c|c|c|}
\hline & $\begin{array}{l}\text { Right 'l'ibia, } \\
\text { Cm. }\end{array}$ & $\begin{array}{c}\text { Left Tibia, } \\
\text { Cm. }\end{array}$ \\
\hline Length $\ldots \ldots \ldots \ldots \ldots \ldots \ldots$. & 38.8 & 38.0 \\
\hline Diameter of shaft $\ldots \ldots \ldots, \ldots, \ldots, \ldots, \ldots, \ldots, \ldots, \ldots, \ldots, \ldots$, & 2.6 & 2.6 \\
\hline Diameter of medullary canal. . & 2.4 & 1.9 \\
\hline 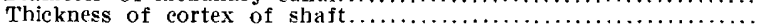 & 0.1 & 0.35 \\
\hline
\end{tabular}

the cancellous bone of its extremities. The medullary canal was markedly increased in diameter. The cortical bone of the shaft was thin and porous. The diameter of the shaft was not decreased. The right tibia measured slightly longer than the left (Fig. 5).

CASE 6.-Fracture. A white man, aged 56, two years previously was struck by a heavy piece of lumber which broke both bones of the left leg. The fracture was compound, but no suppuration followed, and the small open wound closed in a few days. The fracture was treated with plaster but failed to unite. The patient had borne no weight on the left leg since the accident. He got about using the right leg and crutches. Examination revealed a nonunited fracture of the left tibia and fibula at the junction of the middle and distal thirds. There was free, painless, false motion at the level of the fracture. Roentgenograms of both tibias were studied, and the character of the bone of the left tibia and fibula was observed at operation, which was performed for the cure of the nonunited fracture.

The bones of the left leg and foot showed extreme bone atrophy. The cancellous bone of the extremities of the long bones and of the entire tarsal bones was very thin. The trabeculae were decreased in number and density. The medullary canal of the long bones was increased in size. The cortex of the shafts of the long bones was thin and porous. 
Changes in Bone Resulting from Lack of Use During Growth.The following cases were chosen as examples showing the changes in bone which result from lack of use during the growing period.

CASE 7.-Peripheral nerze injury. A white girl, aged 9 years, had a single congenital dislocation of the left hip. The deformity was such that the patient got about with a slight limp. There was no apparent muscle atrophy. An open operation was performed, and the dislocation was reduced. Immediately following operation, there was a complete sciatic nerve paralysis. The patient

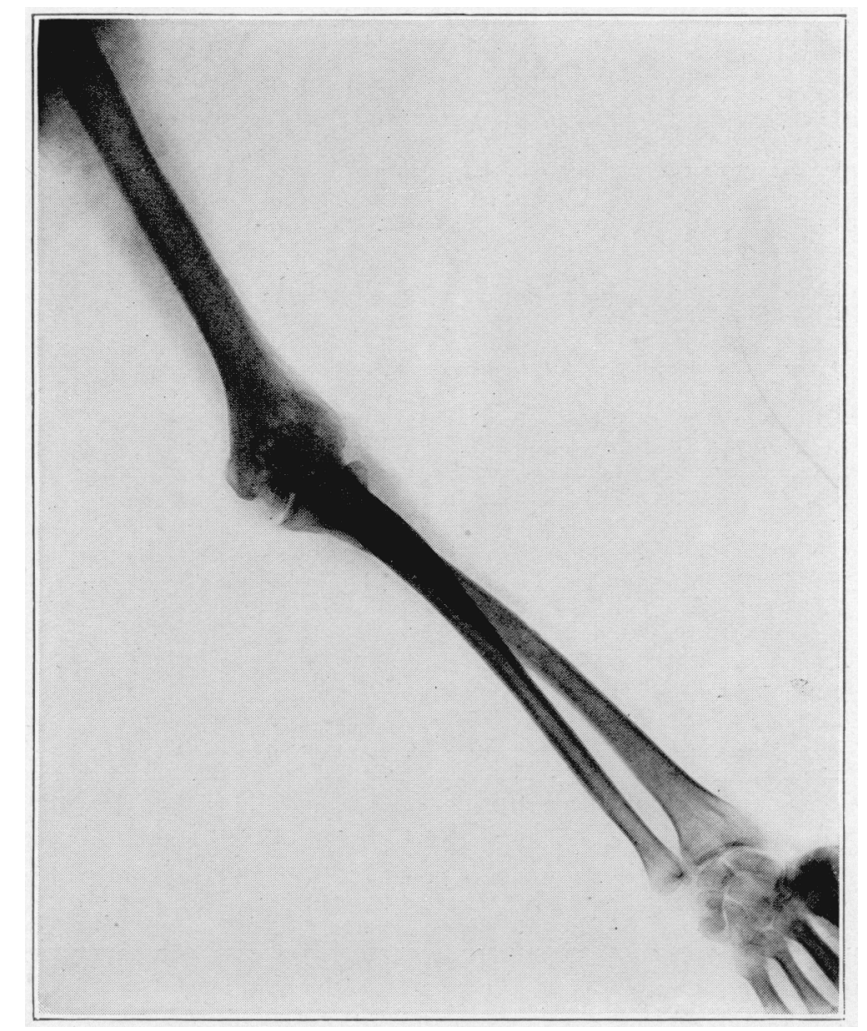

Fig. 3.-Roentgenogram of the bones of the left upper extremity in Case 3. a man, aged 38, suffering from syringomyelia. The first symptoms of the disease appeared twenty-four years previously. The progress had been slow and the sensory paralysis was much more advanced than the motor paralysis. The bones show a moderate degree of atrophy.

was under observation for a period of five years after the nerve injury. At the end of this period there was some recovery of sensation. There was a slight return of power in the hamstring muscles. Otherwise, there was a complete motor paralysis of all muscles supplied by the sciatic nerve, with marked muscle atrophy. The patient was unable to use the leg in walking. Roentgenograms of both lower extremities were made five years after the nerve injury. Those of both tibias were studied in detail. 
The bones of the right leg appeared normal for a 14 year old child. Both epiphyseal cartilages were present in both bones. The contours of both tibias and fibulas were normal. Both bones of the left leg were abnormal. The fibula had a very small shaft. The epiphyses were large in comparison with the shaft, but were smaller than normal. Both epiphyseal cartilages of the fibula were absent. The left tibia showed a decrease in the diameter of the shaft, and a relative increase in the diameter of the medullary canal. The epiphyses of the tibia were large in comparison with the shaft, but smaller than those of the normal tibia. The cortex of the shaft was thinner than that of the right tibia. The proximal epiphyseal cartilage was apparently absent. The distal cartilage showed faintly. The lengths of both tibias and fibulas were diminished (Fig, 7).

Table 5.-Measurements of Bones in Case 7

\begin{tabular}{|c|c|c|}
\hline & $\begin{array}{c}\text { Right Tibia, } \\
\text { Cm. }\end{array}$ & Left Tibia, \\
\hline Length $\ldots \ldots \ldots \ldots$ & 33.5 & 32.5 \\
\hline 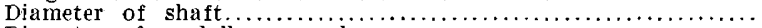 & 2.1 & 1.8 \\
\hline 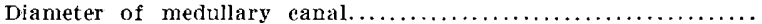 & 1.3 & 1.2 \\
\hline 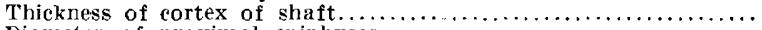 & 0.4 & 0.3 \\
\hline Diameter of proximal epiphyses $\ldots \ldots \ldots \ldots \ldots \ldots \ldots \ldots \ldots \ldots \ldots \ldots$ & 7.0 & 6.5 \\
\hline
\end{tabular}

TABLE 6.-Measurements of Bones in Case 8

\begin{tabular}{|c|c|c|c|c|}
\hline & $\begin{array}{l}\text { Right Tibia, } \\
\text { Cm. }\end{array}$ & $\begin{array}{l}\text { Left:'I'iba, } \\
\text { Cm. }\end{array}$ & $\begin{array}{c}\text { Right Femur, } \\
\text { Cm. }\end{array}$ & $\begin{array}{c}\text { Left Femur, } \\
\text { Cm. }\end{array}$ \\
\hline Length $\ldots \ldots \ldots \ldots \ldots \ldots \ldots \ldots \ldots$ & 28.9 & 30.2 & 35.2 & 36.0 \\
\hline Diameter of shaft............... & 1.5 & $1 . \overline{7}$ & 1.7 & 1.9 \\
\hline Diameter of medullary canal........ & 0.9 & 1.0 & 09 & 0.9 \\
\hline Thickness of cortex................. & 0.3 & 0.35 & 0.4 & 05 \\
\hline Diameter of epiphysis............... & 5.7 & 6.3 & 6.6 & 7.0 \\
\hline
\end{tabular}

TABLE 7.-Measurements of Bones in Case 9

\begin{tabular}{|c|c|c|}
\hline & $\begin{array}{c}\text { Right Radius, } \\
\text { Cm. }\end{array}$ & $\begin{array}{l}\text { Left Radius, } \\
\mathrm{Cm} .\end{array}$ \\
\hline 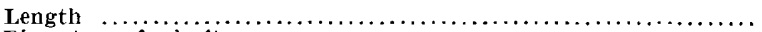 & 19.5 & 25.0 \\
\hline 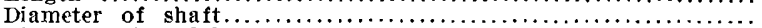 & 1.3 & 1.6 \\
\hline Diameter of medullary canal. . $\ldots \ldots \ldots \ldots \ldots \ldots \ldots \ldots \ldots \ldots \ldots \ldots$. & 0.8 & 0.25 \\
\hline 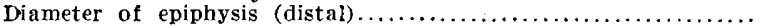 & 2.7 & 3.6 \\
\hline
\end{tabular}

CASE 8.-Spastic paralysis. A colored girl, aged 11 years, had had a right hemiplegia since birth. She was restless and feebleminded and had never walked. The right leg and arm showed the typical picture of complete spastic paralysis. The left arm and leg were not paralyzed.

Roentgenograms of the bones of both lower extremities were studied. All the bones of both extręmities showed distinct evidence of lack of function. The changes in the bones of the right lower extremity were much more marked than in the left (Fig. 8).

CASE 9.-Ischemic contracture. A white boy, aged 17 years, at the age of 10 years fell from a tree and fractured the bones of the right forearm. Splints were immediately applied to the arm. There was a great deal of pain. The splints were not removed for two weeks. When the dressings were removed, there was extensive ulceration of the skin of both anterior and posterior surfaces of the wrist and palm. The fingers could not be straightened. Grad- 
ually a marked flexion contracture developed. The hand had not been used since injury - the thumb was adducted across the palm. There were deep scars on the flexor and extensor surfaces of the wrist, as well as a deep scar on the thenar eminence. The muscles of the forearm were markedly atrophied. There was no evidence of sensory or motor paralysis. The entire forearm and hand were shorter and smaller than normal. The patient did not use the hand.

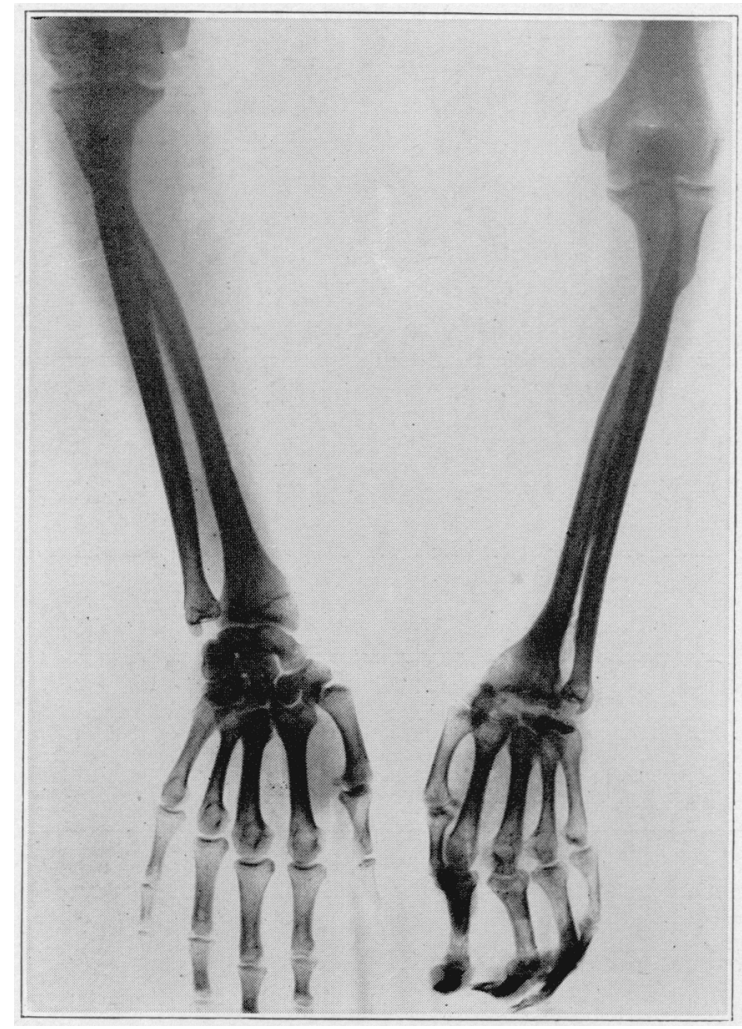

Fig. 4.-Roentgenogram of the bones of both forearms in Case 4, a boy, aged 16 years, suffering from an ischemic contracture of the left forearm, of one year's duration. There is a diminution in size and density of all of the bones of the left forearm and hand. The atrophic changes in the bones of the forearm are more marked in the distal portions of the bones. The distal epiphyseal cartilages of the left ulna and radius are absent.

Roentgenograms of both forearms and hands were studied. There was a marked diminution in the size and length of all bones of the right forearm and hand. The distal end of the radius and ulna showed more marked changes than the proximal ends. The cancellous bone of the distal end of the radius and of the bones of the hand was more porous. The diameter of the shafts of the bones was relatively decreased. The medullary canals were relatively increased. The cortex of the shaft was the same as that of the normal 
extremity. The epiphyseal lines were present in the bones of the left forearm. The epiphyseal lines of the bones of the right forearm had disappeared (Fig. 9).

CASE 10.-Tuberculosis of hip. A white girl, aged 6 years, two years before had begun to limp. One year previously, examination revealed the typical clinical picture of tuberculosis of the hip. There was at this time only slight bone destruction in the right acetabulum. The right knee was slightly swollen and tender. Roentgen-ray examination disclosed no bone destruction at the knee. Tuberculosis of the knee was suspected, but could not be proved. The patient was treated by traction in bed for six weeks, after which a spica cast was applied to the entire right lower extremity. The patient has been continuously in a cast for a year. The cast had been changed four times during this period, but had never been off for more than a day. The patient had been able to get about with crutches and a high sole on the left shoe, for the last three months. For the last six months there had been no fever and the general condition of the patient had been very good.

TABLE 8.-Measurements of Bones in Case 10

\begin{tabular}{|c|c|c|}
\hline & $\begin{array}{c}\text { Right Tibia, } \\
\text { Cm. }\end{array}$ & $\begin{array}{c}\text { Left Tibia, } \\
\text { Cm. }\end{array}$ \\
\hline Length $\ldots \ldots \ldots \ldots$. & 27.2 & 27.0 \\
\hline Diameter of shaft. & 1.3 & 1.6 \\
\hline 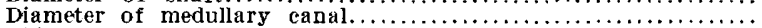 & 1.0 & 1.0 \\
\hline 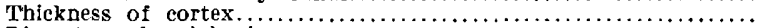 & 0.30 & 0.15 \\
\hline 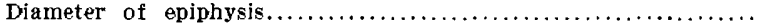 & 5.4 & 5.0 \\
\hline
\end{tabular}

TABLE 9.--Measurements of Bones in Case 11

\begin{tabular}{|c|c|c|c|c|}
\hline & $\begin{array}{l}\text { Right Tibia, } \\
\text { Cm. }\end{array}$ & $\begin{array}{l}\text { Left Tibia, } \\
\text { Cm. }\end{array}$ & $\begin{array}{c}\text { Right Femur, } \\
\text { Cm. }\end{array}$ & $\begin{array}{c}\text { Left Femur, } \\
\text { Cm. }\end{array}$ \\
\hline Length $\ldots \ldots \ldots \ldots \ldots \ldots \ldots \ldots \ldots \ldots \ldots$ & 34.0 & 33.6 & & \\
\hline Diameter of shaft................. & 2.1 & 1.9 & 2.6 & $\dddot{2} .4$ \\
\hline Medullary canal $\ldots \ldots \ldots \ldots \ldots \ldots \ldots \ldots \ldots \ldots \ldots \ldots \ldots$ & 1.4 & 1.3 & 1.6 & $1 . \tilde{z}$ \\
\hline Diameter of epiphysis............... & 7.0 & 6.8 & $\ldots$ & $\ldots$ \\
\hline
\end{tabular}

Examination immediateiy after removal of the cast revealed very little motion in the right hip and knee. There was marked muscle atrophy of all the muscles of the right thigh and leg.

Roentgenograms of all the bones of both lower extremities were studied. The right hip joint showed extensive destruction of the acetabulum and head of the femur. There was no evidence of a tuberculous focus in the region of the knee joint. All bones of the right lower extremity showed extreme atrophic changes. The tibia was chosen for comparative study since this bone was not involved in the disease process.

The right tibia showed a marked decrease in density of the cancellous bone. The diameter of the shaft was decreased; the cortex was thinner; the right tibia was slightly longer than the left; the epiphyseal lines were all present. The epiphyseal lines in the right tibia were abnormally regular (Fig. 10).

CASE 11.-Osteomyelitis of femur. A white girl, aged 12 years, at the age of 6 years had suffered from acute osteomyelitis which involved the distal end of the left femur. The site of the infection was opened and drained. There was a discharge from the bone for a period of one year. The wound then closed, with the gradual reestablishment of normal function in the extremity. For a period of eight months, the left lower extremity was not used. At 
the present time there is slight atrophy of the muscles in the thigh and calf on the affected side. Roentgenograms of the bones of both lower extremities were studied.

All the bones of the left lower extremity were slightly smaller in all measurements. The trabeculae of the cancellous bone were fewer in number but thicker, presenting the appearance of a coarser network. The epiphyseal lines were all present and did not vary on the two sides (Fig. 11).

The patient had a short period of nonuse during the growing period, which was followed by complete return of use of the extremity.

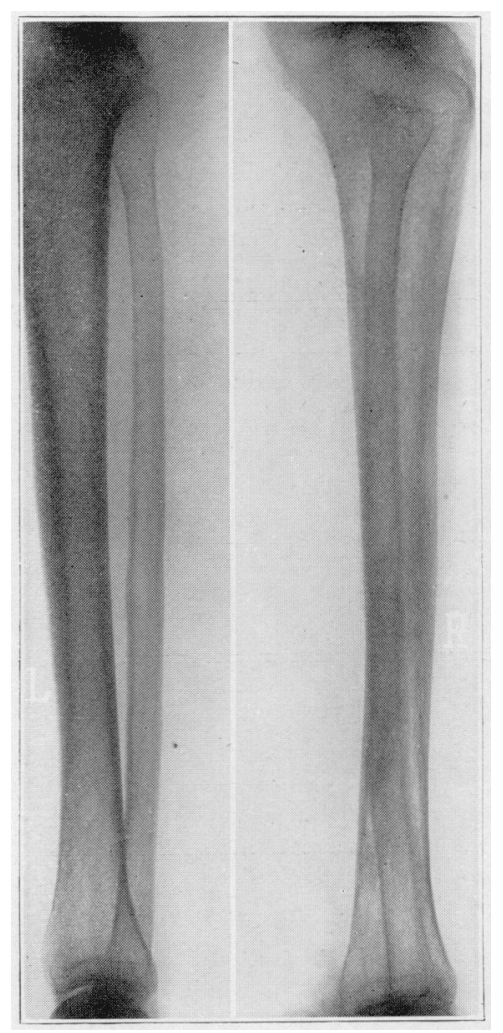

Figure 5

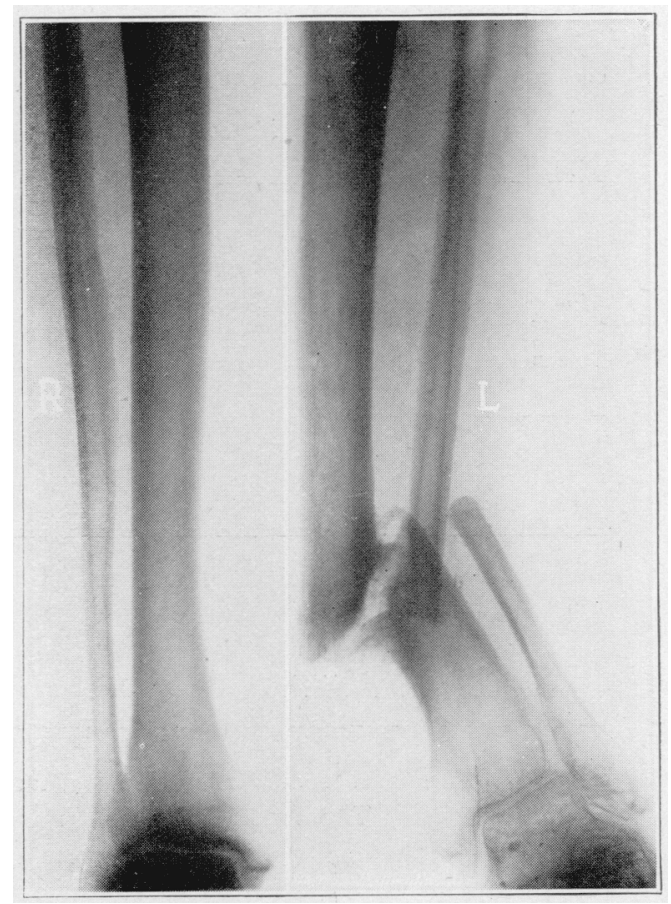

Figure 6

Fig. 5.-Roentgenogram of the hones of both legs in Case 5, a woman, aged 52. who had not used her right leg for a period of six years because of a deformity of the foot which followed an acute infectious process in the tarsus. The bones of the right leg show advanced nonuse atrophy. The thick, compact cortex of the shaft of the right tibia is changed to thin porous bone. The illustration is characteristic of advanced bone atrophy which results from lack of use during the adult period.

Fig. 6.-Roentgenogram of bones of the legs in Case 6, a man, aged 56, with a nonunited fracture of the left leg of two years' duration. The bones of the left leg, foot and ankle show marked atrophy. 
CASE 12.-Fracture. A white boy, aged 14 years, at the age of 8 years fell and fractured the shaft of the right femur. The fracture healed in good position, and function was restored. Since this accident, however, the right femur had been refractured seven times, each time the result of a fall. The patient was first seen by us in October, 1920, at which time there was a lack of union in the eighth fracture of the shaft of the right femur, which had been sustained two months previously. The fracture had been treated by application of a plaster cast. The patient stated that each preceding fracture had been treated in a similar manner. Examination in October, 1920, revealed false motion in the middle third of the right femur. Roentgenograms disclosed lack of approximation of the fragments. Roentgenograms were made of all the bones of the body. There was nothing abnormal except in the bones of the right lower extremity. All bones of this extremity showed atrophic changes. There was marked decrease in the density of the cancellous and cortical bones. The bones were diminished in thickness and length as compared with the corresponding bones of the left extremity. All epiphyseal cartilages were

Table 10-Measurements of Bones in Case 12

\begin{tabular}{|c|c|c|c|c|}
\hline & \multicolumn{2}{|c|}{ October, 1920} & \multicolumn{2}{|c|}{ February, 1922} \\
\hline & $\begin{array}{l}\text { Left Tibia, } \\
\text { Cm. }\end{array}$ & $\begin{array}{c}\text { Right Tibia, } \\
\text { Cm. }\end{array}$ & $\begin{array}{l}\text { Left Tibia, } \\
\text { Cm. }\end{array}$ & $\begin{array}{c}\text { Right Tibia, } \\
\text { Cm. }\end{array}$ \\
\hline Length $\ldots \ldots \ldots \ldots \ldots \ldots \ldots \ldots \ldots$ & 32.3 & 29.8 & 33.3 & 29.9 \\
\hline Diameter $\quad \ldots \ldots \ldots \ldots \ldots \ldots \ldots \ldots \ldots$. & 2.0 & 1.7 & 2.2 & 1.9 \\
\hline Diameter of medullary canal........ & 1.0 & 1.0 & 1.0 & 0.9 \\
\hline Thickness of cortex................ & 0.45 & 0.35 & 0.6 & $0 . \overline{5}$ \\
\hline Diameter of epiphyses.............. & $\ldots$ & $\cdots$ & 7.7 & 6.9 \\
\hline
\end{tabular}

TABLE 11.-Measurements of Bones in Case 13

\begin{tabular}{|c|c|c|c|c|}
\hline & $\begin{array}{c}\text { Right 'Tibia, } \\
\text { Cm. }\end{array}$ & $\begin{array}{l}\text { Left Tibia, } \\
\text { Cm. }\end{array}$ & $\begin{array}{c}\text { Right Fibula, } \\
\text { Cm. }\end{array}$ & $\begin{array}{c}\text { Left Fibula, } \\
\text { Cm. }\end{array}$ \\
\hline Length $\quad \ldots \ldots \ldots \ldots \ldots \ldots \ldots \ldots \ldots$ & 40.0 & 39.0 & 34.0 & 34.0 \\
\hline 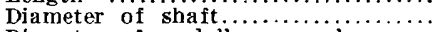 & 2.5 & 2.0 & $\begin{aligned} 0.0 \\
1.0\end{aligned}$ & $\begin{array}{r}0.0 \\
0.5\end{array}$ \\
\hline Diameter of medullary canal. ....... & 1.3 & 1.4 &... & $\ldots$. \\
\hline Diameter of epiphyses............. & 8.5 & 7.6 & $\ldots$ & $\ldots$ \\
\hline 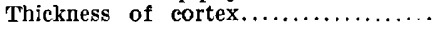 & 0.6 & 0.3 & $\cdots$ & $\cdots$ \\
\hline
\end{tabular}

present (Fig. 12). The fracture was treated by open operation and bone transplantation. The fracture united in twelve weeks. The patient then got about on crutches for a period of about six weeks, after which time he walked with no support. For the last year the patient had been using the extremity, with an extension sole for complete weight bearing. In February, 1922, the entire right lower extremity was smaller and shorter than the left. The measured shortening amounted to 3.5 inches $(8.9 \mathrm{~cm}$.). Roentgenograms of the bones of both lower extremities were obtained.

In this patient, therefore, there was a period between the ages of 8 and 14 years in which there was a marked lack of use of one lower extremity as a result of repeated fractures. Finally there was a year of continuous usefulness of the extremity. Roentgenograms were obtained at the beginning and end of this period of usefulness of the extremity. This permitted the study of the changes which result from lack of use and also the effect on the bones of reestablishment of function. Furthermore, the period of observation was during the latter years of growth of the patient. 


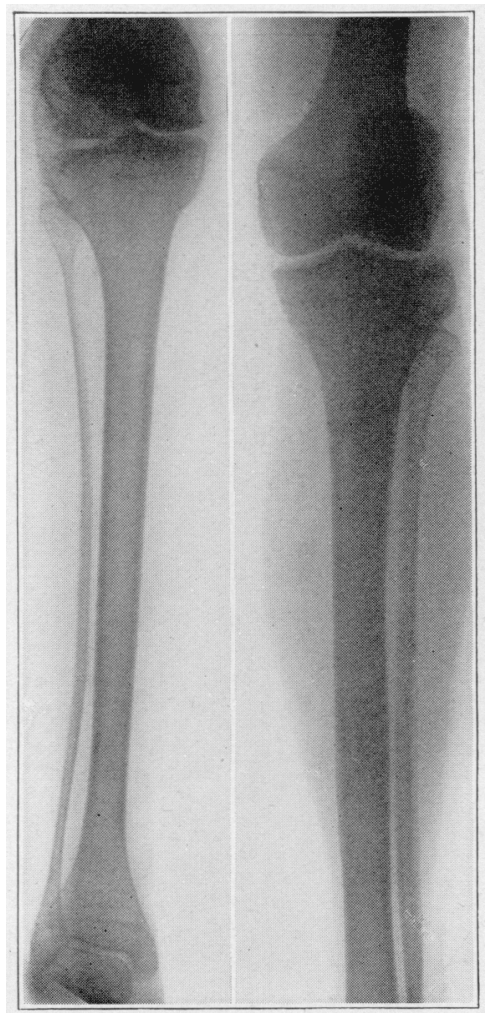

Figure 7

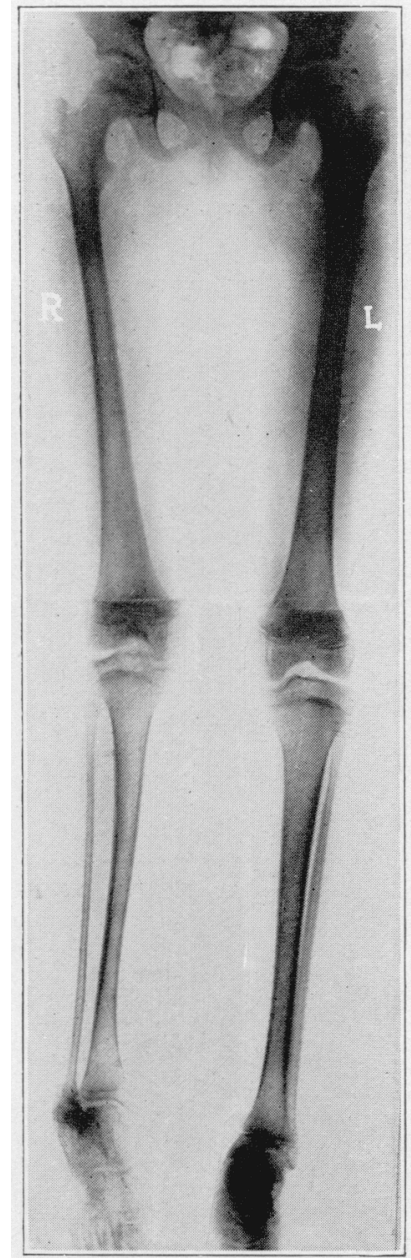

Figure 8

Fig. 7.--Roentgenogram of the bones of the legs in Case 7, a girl, aged 14 years, who had a complete muscle paralysis of the left leg due to injury of the sciatic nerve five years previously. Compare the shape and the appearance of the epiphyseal cartilages of the tibias. The measurements of the bones are recorded in the description of Case 7.

Fig. 8. - Roentgenogram of the bones of the lower extremities in Case 8, a girl, aged 11 years, who had suffered from a right hemiplegia since birth. Compare the bones of the two extremities with the measurements recorded in the description of Case 8 . 
Roentgenograms of the bones of both lower extremities taken in 1922 demonstrated the bones of the affected extremity to be smaller and shorter than those of the normal extremity. The left tilia had increased in all dimensions. The right tibia had increased in thickness but not in length. All epiphyseal cartilages in the bones of the right extremity were absent. The proximal epiphyseal cartilages of the left tibia and fibula were faintly visible. There was a marked difference in the appearance of the cancellous hone of the right tibia from that seen in the left tibia and also from that seen in the right in the roentgenograms studied a year previously. The trabeculae of the can-

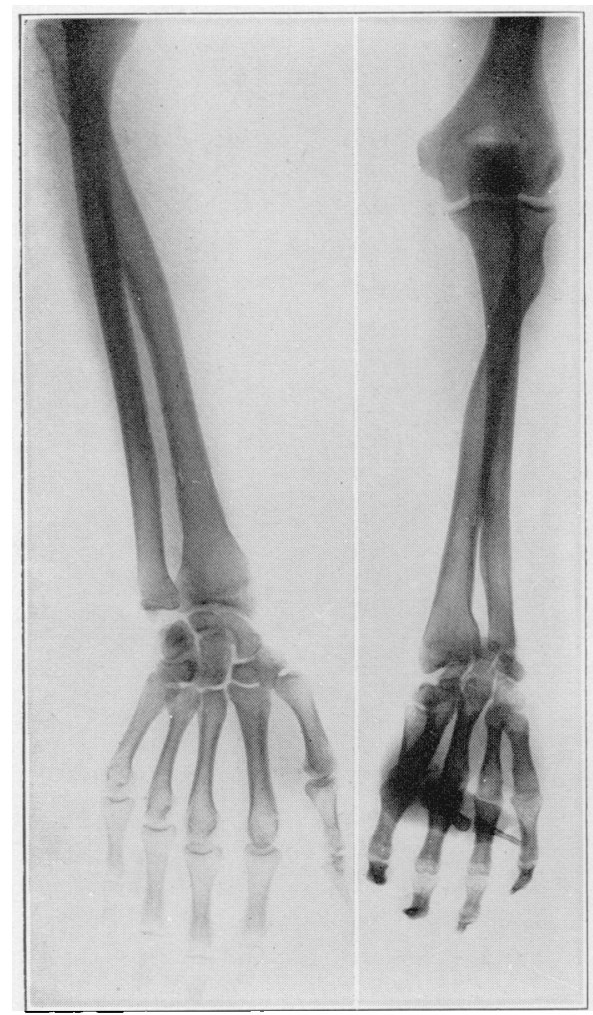

Figure 9

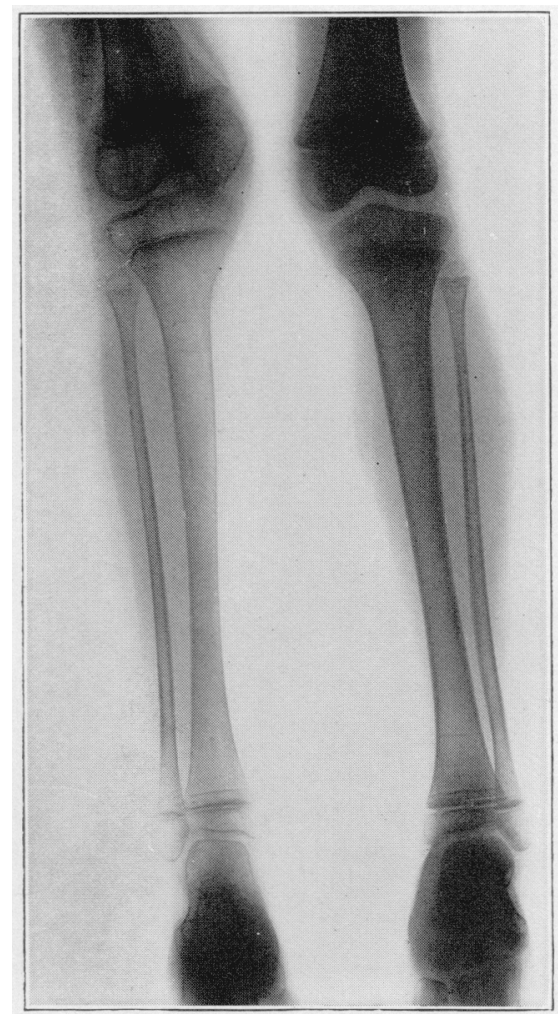

Figure 10

Fig. 9.-Roentgenogram of the bones of the forearms in Case 9, a boy, aged 17 years, with an ischemic contracture of the right forearm and hand. The disproportion of size of the bones of the right forearm and hand may be noted. The disproportion in length is greater than has been olserved in other cases of nonuse. The epiphyseal cartilage may have been injured at the time of onset of the disease.

Fig. 10,-Roentgenogram of the bones of the legs in Case 10, a child, aged 6 years, with tuberculosis of the right hip of two years' duration. The entire extremity had been fixed in plaster for one year. The marked difference in the bones of the extremities may be noted. Compare the atrophic bones of the right leg with the illustrations of bone atrophy resulting from poliomyelitis. 
cellous bone in the right tibia were fewer in number than in the corresponding areas of the left tibia, the individual trabeculae of the right tibia were thicker than in the left tibia and also thicker than in the right tibia of one year ago (Fig. 13).

CASf 13.-Congenital deformity. A white boy, aged 15, was born with a unilateral left talipes equinovarus of marked degree. The patient began to walk at the usual age. There had been one operative effort made to correct the deformity. At the time of examination the patient walked without artificial support. The weight was borne on the distal ends of the lateral metatarsals. There was a marked limp and disability in gait. The muscles of the left thigh and calf were much smaller than those of the right.

Roentgenograms of the bones of both legs were studied. The bones of the right leg appeared normal. The bones of the left leg were thinner and shorter than normally. The cancellous bone was more porous than normally and the cortex of the shaft was diminished in thickness. The left fibula was strikingly thin. It was interesting to note, however, that the length of the left fibula and the right fibula was the same. All epiphyseal cartilages were present. Those in the bones of the left leg were more nearly closed than those in the bones of the right leg (Fig. 14).

TABle 12.-Measurements of Bones in Case 14

\begin{tabular}{l}
\hline \hline \\
$\begin{array}{c}\text { Roentgenograms } \\
\text { Oet. } 28,1920\end{array}$
\end{tabular}

Case 14.-Poliomyclitis. A girl, aged 5 years, was first seen in September, 1920 , suffering from an acute attack of anterior poliomyelitis. The paralysis was complete in all extremities. The patient was under observation at the time of examination. There had been some recovery of motion in both upper extremities; but the lower extremities remained in a state of completely flaccid paralysis. The patient had been confined continuously to bed and to a chair. Roentgenograms of the bones of both legs were made Oct. 20, 1920, Jan. 19, 1921, and Dec. 12, 1921.

Roentgenograms made Oct. 28, 1920, one month after onset of the disease, revealed normal appearing bones. In the roentgenograms made Jan. 19, 1921, three months later, there was a marked change in the appearance of the bones of both legs. The cancellous bone was much more porous. The cortical bone of the shaft was much thinner and showed linear striae of decreased density. There was a slight increase in length of the bones of both legs. Measurements of the diameters of the shafts and medullary cavities cannot be accurately compared because the roentgenograms taken in October, 1920, were lateral views and those made in January, 1921, were anteroposterior views.

The roentgenograms made Dec. 12, 1921, fourteen months after the onset of the disease, were taken under the same conditions as those made Jan. 19, 1921. A comparison of these two roentgenograms, therefore, demonstrates accurately 
the progress of the bone changes during a period of eleven months of complete lack of use in a growing child. The bones of both legs had become exceedingly thin. The trabeculae of the cancellous lone were much fewer and smaller. The thickness of the cortex had decreased markedly. The length of the bones had increased. The diameter of the shafts had decreased. The diameter of the medullary canals had increased. The width of the epiphyses had increased. Thus, the contours of the bones had changed (Figs. 15, 16 and 17).

CAse 15.-A white woman, aged 25, at the age of 4 years had an attack of acute anterior poliomyelitis which resulted in a complete paralysis of all the muscles of the left leg and a partial paralysis of the left thigh. Since the onset of the paralysis, the left lower extremity had not been used for walking. The patient had always walked with crutches and there had been no attempt at any time to make use of the paralyzed extremity either with or without artificial support. Examination revealed complete paralysis of the leg with marked muscle atrophy. The adductor group and the psoas muscles of the thigh had some power, otherwise the thigh muscles were completely paralyzed and atrophied.

TABLE 13.-Miasuremint of Bones in Casi 15

\begin{tabular}{|c|c|c|}
\hline & $\begin{array}{c}\text { Right 'libia, } \\
\text { Cm. }\end{array}$ & $\begin{array}{l}\text { Left Tibia, } \\
\text { Cm. }\end{array}$ \\
\hline Length $\ldots \ldots \ldots \ldots \ldots \ldots$ & 40.0 & 34.6 \\
\hline 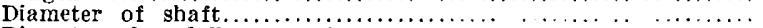 & 2.7 & 1.9 \\
\hline 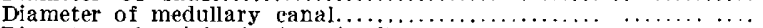 & 1.7 & 1.1 \\
\hline 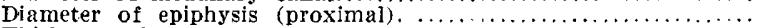 & 7.8 & 6.6 \\
\hline 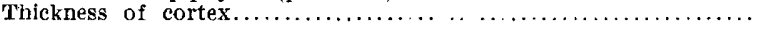 & 0.5 & 0.4 \\
\hline
\end{tabular}

TaBle 14-Measurements of Bones in Case 16

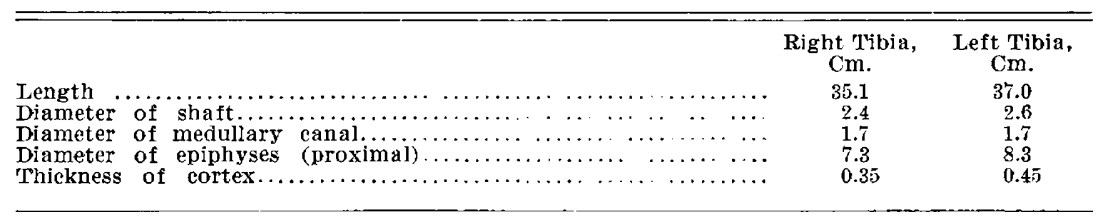

Roentgenograms of the bones of both lower extremities were studied. All of the bones of the left lower extremity, including the bones of the left pelvic girdle, were diminished in size and density. There was an extreme coxa valga deformity of the left femur, associated with a lack of development of the great trochanter and a relative overdevelopment of the lesser trochanter. The acetabulum was small and shallow. All epiphyseal cartilages were absent. The tibias were chosen for detailed comparative study. The right tibia appeared normal. The left tibia was shorter. The diameter of the shaft was diminished. The epiphyses were smaller than those of the left tibia, but in comparison to the size of the shaft they were large. The cancellous bone was more porous, and the cortex of the shaft was thin (Fig. 18).

CASE 16.-A white woman, aged 28, when 1 year old had an attack of acute anterior poliomyelitis which resulted in a complete permanent paralysis of all the muscles of the right leg and a partial paralysis of the thigh. The extensor muscles of the thigh were paralyzed. There was power in the hamstring muscles. There was marked muscle atrophy of the leg and less marked atrophy of the thigh. In spite of the extent of the paralysis, the patient had continu- 
ously used the leg for walking. Roentgenograms of the hones of both lower extremities were studied. Considering the marked difference in muscles of the two legs, there was surprisingly little difference in the appearance of the bones of the two legs. The right tibia was slightly shorter and thinner. The cancellous bone was only slightly more porous. The diameter of the shaft was slightly decreased (Fig. 19).

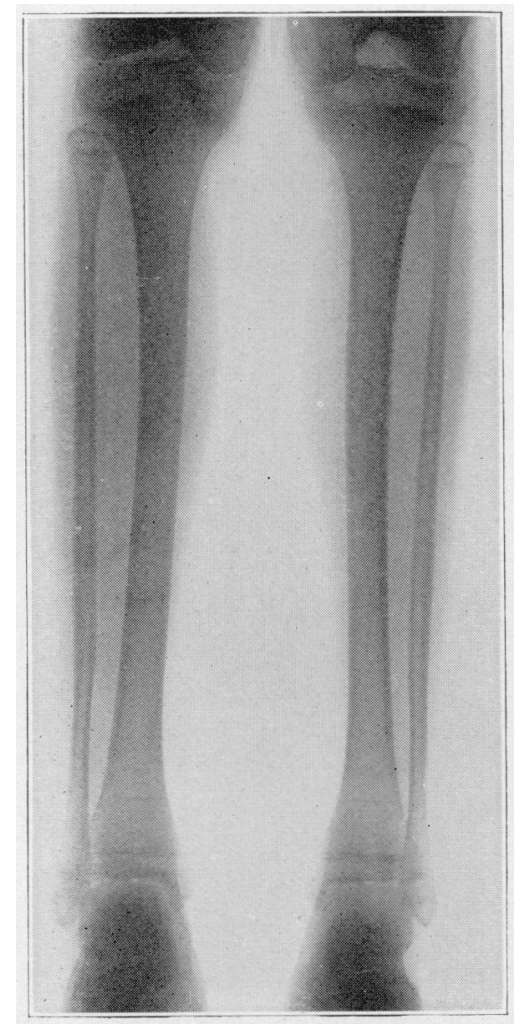

Figure 11

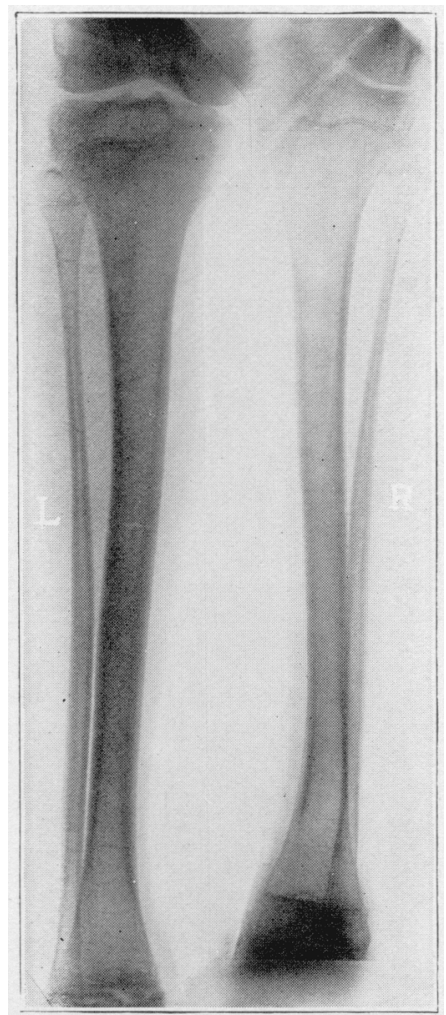

Figure 12

Fig. 11.-Roentgenogram of the bones of the legs in Case 11, a girl, aged 12 years, who did not use the right leg for a period of about eight months at the age of 6 years, owing to acute osteomyelitis of the distal end of the femur. The recovery from the disability was complete. The unmistakable evidences of lack of use during the growing period are seen in the abnormal shape and size of the bones of the right leg.

Fig. 12.-Roentgenogram of the bones of the legs in Case 12, a boy, aged 14 years, who had sustained repeated fractures of the right femur. These roentgenograms were made two months after the last fracture, at which time there was lack of union of the fragments due to malposition. The bones of the right leg show marked atrophic changes and growth disturbance. All epiphyseal cartilages are distinct, but they are thicker in the bones of the left leg. Compare with Figure 13. 


\section{iII. RELATION lBETWEEN CHANGES IN BONE AS A RESLlt OF LACK OF USE AND TIIE CALSE OF THE NONUSE}

From the stucly of the changes in bones which followed lack of use from various causes in both children and adults, there was no evidence that the cause of the lack of use affected these changes in any manner. The same atrophic changes in bone were observed when the lack of use was due to anterior poliomyelitis, spastic paralysis, peripheral nerve injury, Friedreich's ataxia. pseudomuscular atrophy, syringo-

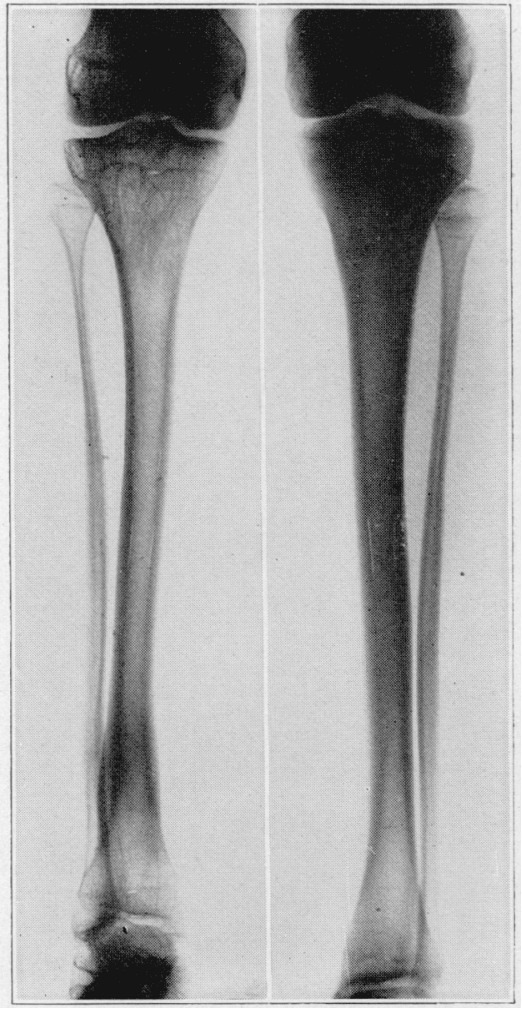

Figure 13

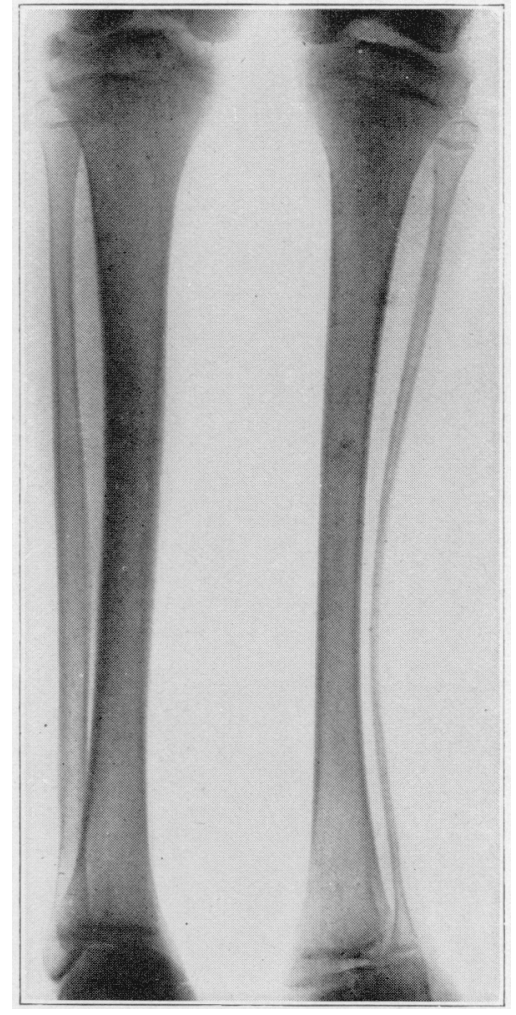

Figure 14

Fig. 13.-Roentgenogram of the bones of the legs in Case 12, after healing of the fracture of the femur and continuous use of the extremity for a period of about one year. The increase in thickness of the cortex of the shaft of the right tibia and the increased strength of the struts of the cancellous bone may be noted. The epiphyseal cartilages are absent in the bones of the right leg. Compare with the measurements recorded in the description of Case 12.

Fig. 14.-Roentgenogram of the bones of the legs in Case 13, a boy, aged 15 years, with a left congenital clubfoot. The bones of the left leg show the effects of incomplete function during the growing period. The filula shows more change than the tibia on account of the position of the foot. 
myelia, chronic arthritis, tuberculosis of bone, pyogenic osteomyelitis, contracture, fracture, congenital deformities and astasia abasia. The character of the changes was the same in all instances. The amount of the changes varied directly with the extent of the lack of use. There was absolutely no evidence that bone atrophy was ever the result of specific nerve influence on bone, and it is, therefore, unwarranted to assume that bone atrophy is ever a neurotrophic phenomenon. To emphasize this important point, Figures 7, 10, 12 and 17 show the changes in the tibias of children affected by anterior poliomyelitis, peripheral nerve injury, tuberculosis of the hip and fracture of the

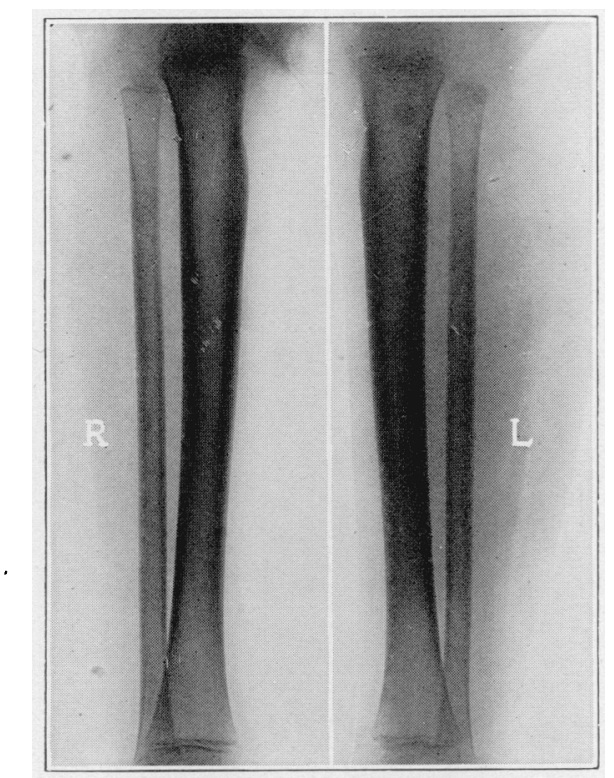

Fig. 15.-Roentgenogram of the bones of the legs in Case 14. one month after the onset of an attack of acute poliomyelitis. The bones of both legs appear normal.

femur, and Figures 1, 2, 3, 5 and 6 show the changes in the bones of adults which followed peripheral nerve injury, spastic paralysis, syringomyelia, fracture and infectious disease.

\section{CHARACTER OF CHANGES IN ADULTS}

The initial atrophic changes in bone due to nonuse of an extremity are the same regardless of the age of the individuals. The ultimate result of the changes in the bones of an extremity which is not used is different in the person who has reached his complete growth from 
that in the person who is in his growing period at the time of onset of nonuse. In the former instance, the process of bone atrophy is operating alone. In the latter, the process of bone atrophy is associated with the process of growth which is inhibited but not arrested by nonuse.

The changes in bone which result from lack of use during adult life are such that the general shape and contour of the bone as a

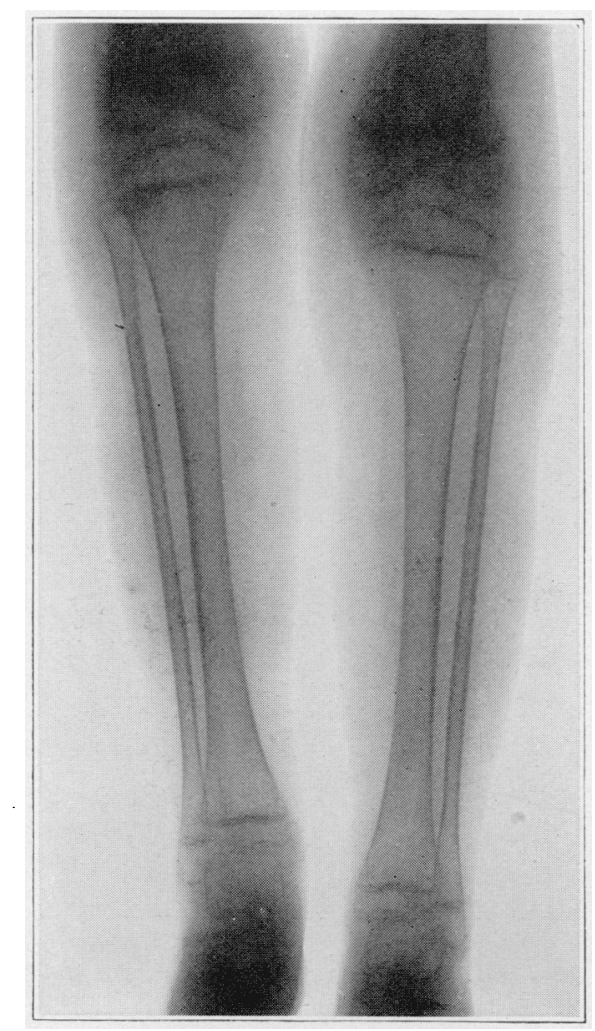

Fig. 16.-Roentgenogram of the bones of the legs in Case 14, made three months after those shown in Figure 15. The amount of atrophic change which has taken place may be noted.

whole are only slightly modified. The diameter of the shaft may be very slightly clecreased. The length is not changed. The medullary canal is increased in diameter, prodlucing a corresponding diminution in the thickness of the cortex, which after a long period of nonuse is reduced to a thin bone shell. The cancellous bone becomes much more porous, with fewer and thinner trabeculae. After a long period of nonuse, the compact bone of the shaft becomes porous. This 
porosity explains the linear striae seen in the roentgenogram. Various degrees of bone atrophy due to nonuse during adult life are shown in Figures 1, 2, 3, 5 and 6 .

v. CIIARACTER OF CHANGES DLRING PERIOD OF GROWTH

The changes in bone which result from lack of use during the growing period are of particular interest because two distinct processes are operating together, and the ultimate result is a marked change in the shape and contour of the whole bone. The bone is smaller both

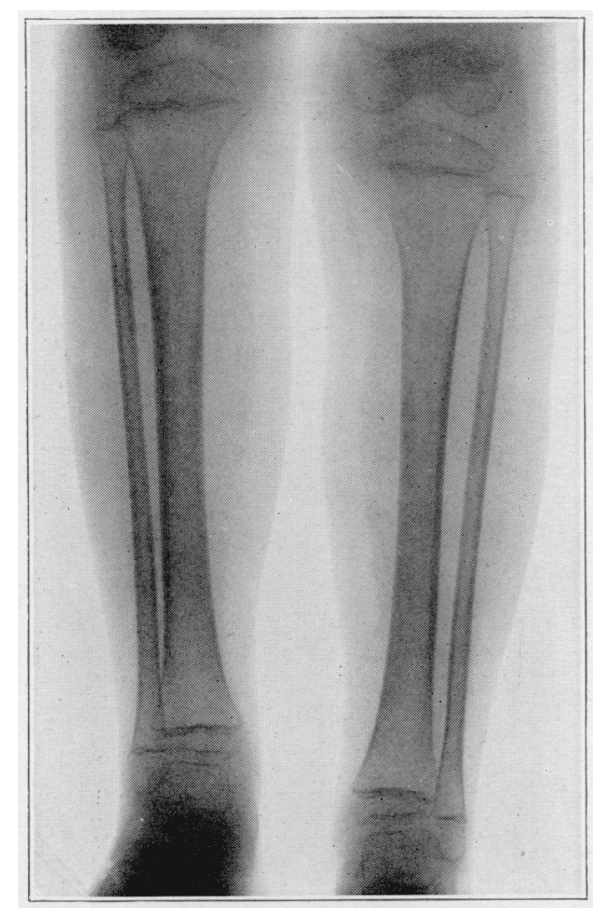

Fig. 17.-Roentgenogram of the bones of the legs in Case 14, made fifteen months after those shown in Figure 15. The further progress of the atrophic changes may be noted. Compare the illustrations with the measurements recorded in the description of Case 14.

in length and thickness; the decrease in thickness is more noticeable than that in length. Furthermore, the diminution in thickness is more marked in the shaft than in the epiphysis, producing an effect of sudden enlargement at the epiphyseal regions. The thickness of the cortex relative to the diameter of the bone shows a change which is small compared with that seen in bone atrophy occurring during aclult life. Comparative measurements of the thicknesses of the entire bones and 
the diameters of the medullary canals show that the medullary canal of the nonused bone is always larger compared with the thickness of the same bone, although it may be actually smaller than the medullary canal of the corresponding bone of the used extremity. There may also be a difference in the shape of the cross section of the bones, comparing used with nonused; for example, the cross section of a normal used tibia is triangular in outline while the cross section of a tibia which has not been used during the growing period more nearly approaches a circle.

The various stages of the combined effect on bones of nonuse and growth are shown in Figures $17^{\circ}$ and 18.

\section{EFFECT OF NCNUSE ON GROWTH OF BONE}

The effect of lack of use on the process of growth of bones deserves special comment. That growth in length and thickness of bones takes place in complete absence of any use whatever is generally known. It is also well recognized that lack of use of one extremity during the period of growth will result ultimately in a short extremity. Two causes of this phenomenon are possible. The bones may grow at a decreased rate, or growth may stop earlier in the nonused extremity. The distinction and relative importance of these two factors have not been appreciated.

From the study of the cases of nonuse during the period of growth, it is clear that lack of use of an extremity results both in inhibition of growth and in an abnormally early cessation of growth in bones.

For example, in a case of anterior poliomyelitis in which there was complete lack of use in one extremity from four to nine years, there was a difference of $1.5 \mathrm{~cm}$. in the lengths of the tibias. In another case of poliomyelitis in which there was a complete unilateral lack of use from four to twenty-five years, there was a difference in the lengths of the tibias of $3.4 \mathrm{~cm}$. In a case of fracture of the femur in which the disability extended from eight to fourteen years, the tibias measured 29.8 and $32.3 \mathrm{~cm}$., a difference of $2.5 \mathrm{~cm}$. At this time the epiphyseal cartilages were present in both tibias. The same patient was studied again at the age of 15 , at which time the epiphyseal carti'age was absent in the atrophied tibia and present in the used tibia. The tibias at this time measured $29.9 \mathrm{~cm}$. and $33.3 \mathrm{~cm}$., a difference of $3.4 \mathrm{~cm}$., the increase in difference cluring the ages of 14 and 15 being due almost entirely to a cessation of growth in the tibia of the nonused extremity and a continuation of growth in the tibia of the used extremity.

The effect of the lack of use during the period of growth on the contour of bones was typically shown in Case 14 , in which the bones 
of the leg were studied for a period of thirteen months from the beginning of the nonuse. Following the onset of the paralysis, the bones began to change in shape. The length increased. There was a contintious diminution in the diameter of the shaft. The diameters of the epiphyses continued to increase. The bone, therefore, in this period, changed in contour corresponding to that always found in bones of

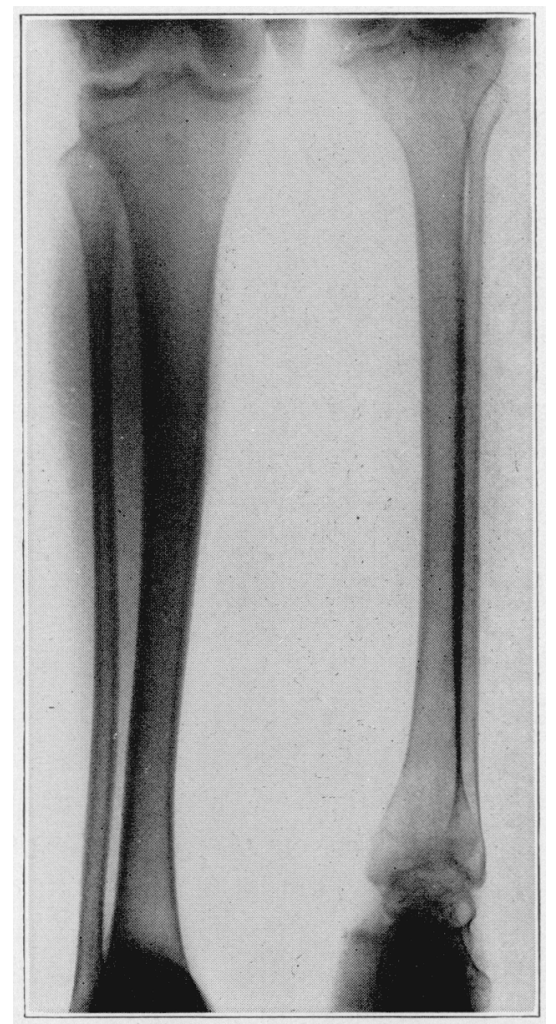

Fig. 18. - Roentgenogram of the bones of the legs in Case 15, a woman, aged 25, with complete paralysis of the left leg and partial paralysis of the left thigh as a result of an attack of acute poliomyelitis at the age of 4 years. The extremity had not been used. The marked changes in the bones of the left leg may be noted. Compare with Figure 19.

nonused extremities during the period of growth, namely, a small round shaft with relatively large flaring epiphyses (Figs. 14, 15, 16, 17 and 18).

\section{EFFECT OF NONUSE ON REGENERATION OF BONE}

The effect of bone atrophy on regeneration of bone has been previously studied experimentally by us. It was found that bone atrophy 
did not affect the process of bone regeneration. The proof of this conclusion has been confirmed by this clinical study. In Case 12, in which there was repeated fracture of the femur associated with extreme bone atrophy, each fracture united promptly when apposition of fragments was secured. In another case of extreme bone atrophy due to twelve years' lack of use of one lower extremity because of tabes dorsalis and a Charcot's hip joint, a fracture of the femur produced a large callus in four weeks.

\section{RECOVERY FROM BONE ATROPHY}

An appreciation of the marked changes in the bones of an extremity which result from the lack of use of this extremity naturally leads to a consideration of the character and quantity of changes which may follow a reestablishment of function in the extremity. For the study of the process of recovery from bone atrophy, two groups of cases have been used. One group consisted of cases in which the history made it practically certain that the bones had previously been in a marked state of atrophy from nonuse. In these cases the bones were studied in comparison with a previous state presumed to have existed from our experience in other cases. In a second group of cases the bones were studied during the actual period of reestablishment of use. A period of two years is relatively short for a study of the second group of cases.

In Case 16 there was an attack of acute poliomyelitis at the age of 1 year, which resulted in a complete permanent paralysis of all the muscles of the leg. The patient, however, learned to walk during childhood and continued to use the extremity until she was observed at the age of 28 years. There was certainly a period after the onset of the paralysis in which the bones of the paralyzed leg were markedly atrophic. The end-results of establishment of use of the extremity, however, was that there were only slight differences in size and contour of the tibia.

In Case 11 there was lack of use of one lower extremity for a period of about eight months at the age of 6 years and a subsequent apparent, comp'ete restoration of function. The patient was studied at the age of 12 years. At this time there was a difference in the size and contour of the tibia. The disease process was a "mild" osteomyelitis of the distal end of the femur.

In Case 12 the effect of one year's continuous use of an extremity in which the bones were atrophic from lack of use were studied in a boy between 14 and 15 years of age. During this period there was a marked increase in the thickness of the cortex of the shaft. The diameter of the shaft increased and the diameter of the medullary canal decreased. The thickness of the individual trabeculae of the 
cancellous bone increased. There was, however, no evidence of an increase in the number of trabeculae per unit of area. In a case of tuberculosis of the knee in a woman, aged 30, who had not used the left lower extremity since she was 17 years old, roentgenograms revealed marked atrophy of all the bones of the extremity. The left knee was fixed in a position of flexion at 45 clegrees (Fig. 20). The knee

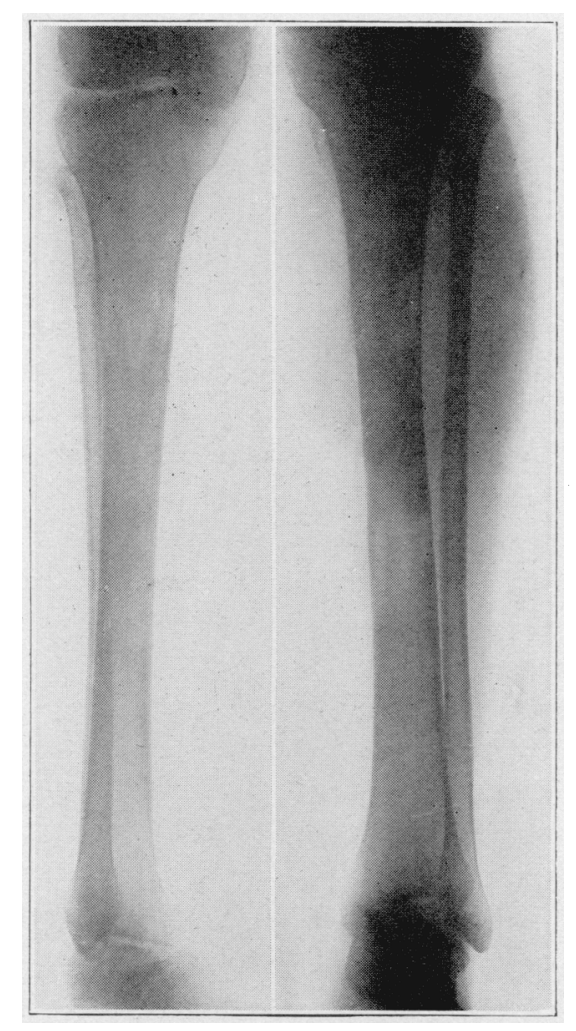

Fig. 19.-Roentgenogram of the bones of the legs in Case 16, a woman. aged 28, with complete paralysis of the muscles of the right leg and a partial paralysis of the muscles of the right thigh as a result of an attack of acute poliomyelitis at the age of 1 year. The patient learned to use the extremity for walking, and it has becn used continuously in spite of extensive paralysis. The bones of the right leg show atrophic changes, but these changes are much less marked than those found in Case 15, in which there was an equal amount of muscle paralysis but complete lack of use.

joint was excised and the patient was kept in a cast for a period of six months. Roentgen-ray examination revealed a further progress of the bone atrophy. The cast was removed and the patient began to use the extremity. Roentgen-ray examinations were then made at 
intervals for a period of two years. During the last year the patient was walking on the leg with no other inconvenience than a stiff knee. After the reestablishment of a useful extremity there was a continuous change in the bones. The thickness of the cortex of the shafts of the bones increased to a marked degree. The trabeculae of the cancellous bone increased in thickness. There was, however, no evilence of the formation of new bone trabeculae (Fig. 21). The thickness of the

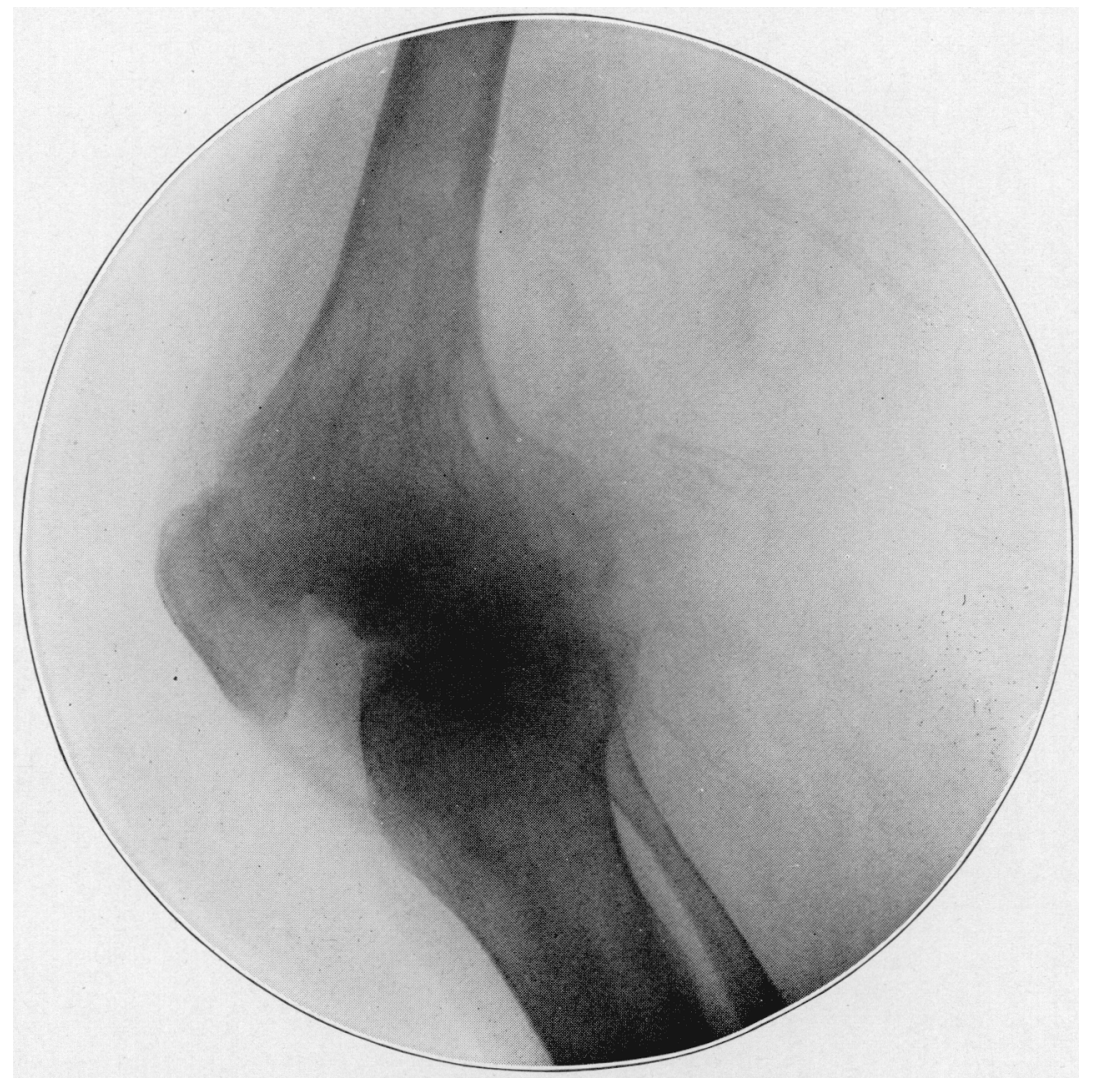

Fig. 20.--Roentgenogram of the knee of a woman, aged 30. showing marked atrophic changes associated with tuberculosis of the knee joint. Compare the thickness of the cortex of the femur and the appearance of the cancellous bone with that shown in Figure 21.

cortex of the shafts of the bones still remained much less than in the corresponding bones of the extremity which had been continuously used since birth.

From the study of these and other cases, therefore, certain conclusions may be drawn as to the recovery from bone atrophy. If the lack of use is during the period of growth, there will be permanent changes in the size and shape of the affected bones. The reestablish- 
ment of use will not result in a sufficiently increased rate of growth to make up for the loss which has occurred during the period of nonuse. It is obvious that to bring this about it would be necessary for a rate of growth above normal to take place. If the lack of use is during the adult period, the shape and size of the bones are not materially changed, and the reestablishment of use results in only an increase in the thickness of the existing parts of the bone. It is partic-

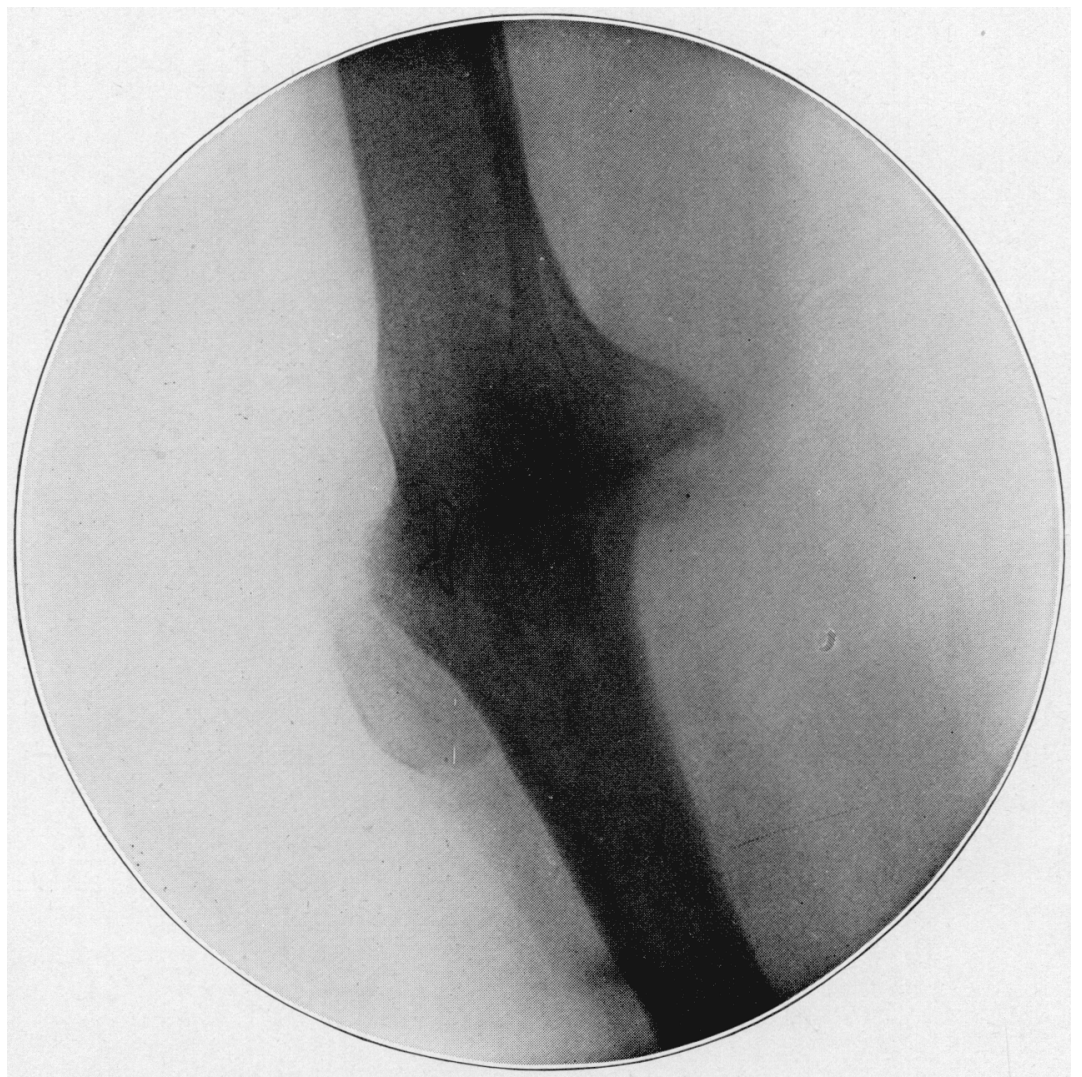

Fig. 21.-Roentgenogram of the same knee shown in Figure 20, two years later, during which time the knee joint was resected and use of the extremity had been reestablished. The marked increase in thickness of the cortex of the femur and the increase in density of the trabeculae of the cancellous hone may be noted.

ularly interesting that lack of use results in a complete disappearance of part of the trabeculae of the cancellous bone. On reestablishment of use, these trabeculae are not reformed; but the existing trabeculae increase in thickness to a legree greater than normal. This results in the cancellous bone becoming a coarser network of struts of greater 
thickness. It is, therefore, often possible from examination of roentgenograms of bones to detect unmistakable evidence of previous periods of lack of use and to predict with some degree of accuracy the period in the patient's life during which the extremity was not used. This statement is particularly applicable to instances in which the lack of use was unilateral.

The changes in bones resulting from lack of use and the recovery from the changes after the reestablishment of use have in all instances already referred to occurred as a result of diseases of the extremities. In a single instance in which a white woman, aged 48 , was confined to bed for a period of one year incidental to repeated operations for intra-abdominal disease, it was found that all the bones of the extremities showed marked atrophy. The fact that bone atrophy occurs as a result of confinement in bed is a matter of considerab'e clinical interest, particularly as it concerns children. The material which has been studied has not been sufficient to permit drawing definite conclusions, except to state that long confinement results in atrophic changes in the bones.

\section{SUMMARY}

It may be stated that these observations are eviclence for the truth of a general theory of bone atrophy. Bone atrophy and recovery from bone atrophy are manifestations of the function of bone cells to produce bone matrix, which is in whole or in part distinct from the function of the bone cells to regenerate themselves. Bone atrophy and recovery from bone atrophy are processes which are not necessarily associated with cell death or cell proliferation. Regeneration is a process which is directly the result of cell multiplication. 